\title{
Localisation of a mutation producing autosomal dominant polycystic kidney disease without renal failure
}

MARKKU RYYNANEN*, MARTI M DOLATA†, ERKKI LAMPAINEN*, AND STEPHEN T REEDERS $\dagger$

From *the Departments of Obstetrics and Gynaecology and Nephrology, Central University Hospital Kuopio, Finland; and the Nuffield Department of Clinical Medicine, John Radcliffe Hospital, Oxfora OX3 9DU.

SUMMARY A four generation Finnish family was identified with atypical features of aduf̂ polycystic kidney disease. All members of the extended pedigree were asymptomatic and none had developed renal failure. Previous studies have shown close linkage between the aduff polycystic kidney disease locus and the $\alpha$ chain of human haemoglobin on chromosome 16 , b通

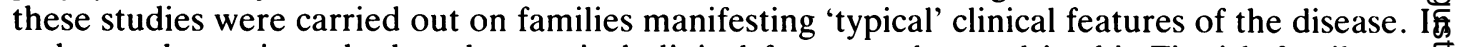
order to determine whether the atypical clinical features observed in this Finnish family were produced by a mutation at the same or a second locus, linkage studies were carried out using highly polymorphic DNA marker from the $\alpha$ globin cluster. Here we show that the mutation producing the disease in this Finnish family is also closely linked to $\alpha$ globin.

Adult polycystic kidney disease (APKD) is one of the commonest autosomal dominant genetic diseases of man, ' with a frequency of 1 in 1000 . In addition to renal disease, patients have an increased incidence of subarachnoid haemorrhage, ${ }^{2}$ renal tumours, ${ }^{3}$ and non-renal cystic manifestations. ${ }^{3}$ There is, however, a marked variation in expression of APKD. A number of APKD families have been described in which there are cases of childhood onset of symptomatic renal disease. ${ }^{4}$ On the other hand, the discrepancy between the clinical and necropsy frequencies of the disease suggests that the morphological changes in APKD are not always associated with functional renal impairment. ${ }^{5}$

Dalgaard" provided some evidence that clinical expression of APKD was similar for patients within each family. More recent studies suggest that there is marked heterogeneity of the APKD phenotype within the whole population of affected patients, ${ }^{8}$ but families have not been examined to determine what might be the genetic contribution to differences in expression. The advent of a genetic linkage marker for APKD" 10 enabled us to begin to examine the possibility that mutations at more than one locus are responsible for at least part of the

Received for publication 24 December 1986. Revised version accepted for publication 20 March 1987. observed phenotypic heterogeneity. In all familie studied so far, linkage has been shown between APKD and the $\alpha$ globin locus on the short arm of chromosome $16 .{ }^{9-19}$ Here we examine a family witb atypical features of APKD to determine whether the observed differences in the clinical pattern arè produced by a mutation which is also linked to $\vec{\varepsilon}$ globin or by a mutation at a second unlinked locus

\section{Patients and methods}

The patients were all Europeans from a single Finnish family (FIN PK1) and were related as show in the figure. The first diagnosis of APKD in th family was unusual in that it resulted from the incidental finding of palpable kidneys during the early neonatal period in patient V.2. The presence of bilateral polycystic kidney disease was confirmed his computer assisted tomography (CT). During the neonatal period, the proband was asymptomatic with normal renal function. She was thorough investigated at one and a half years of age. At tha time she had no symptoms and her blood pressure serum creatinine, and urinary concentrating abiligy were normal. Intravenous pyelography was norma but cysts were seen bilaterally on ultrasonographi臀 examination. She remains well with normal rena: function at four years of age. Both parents of the 462 


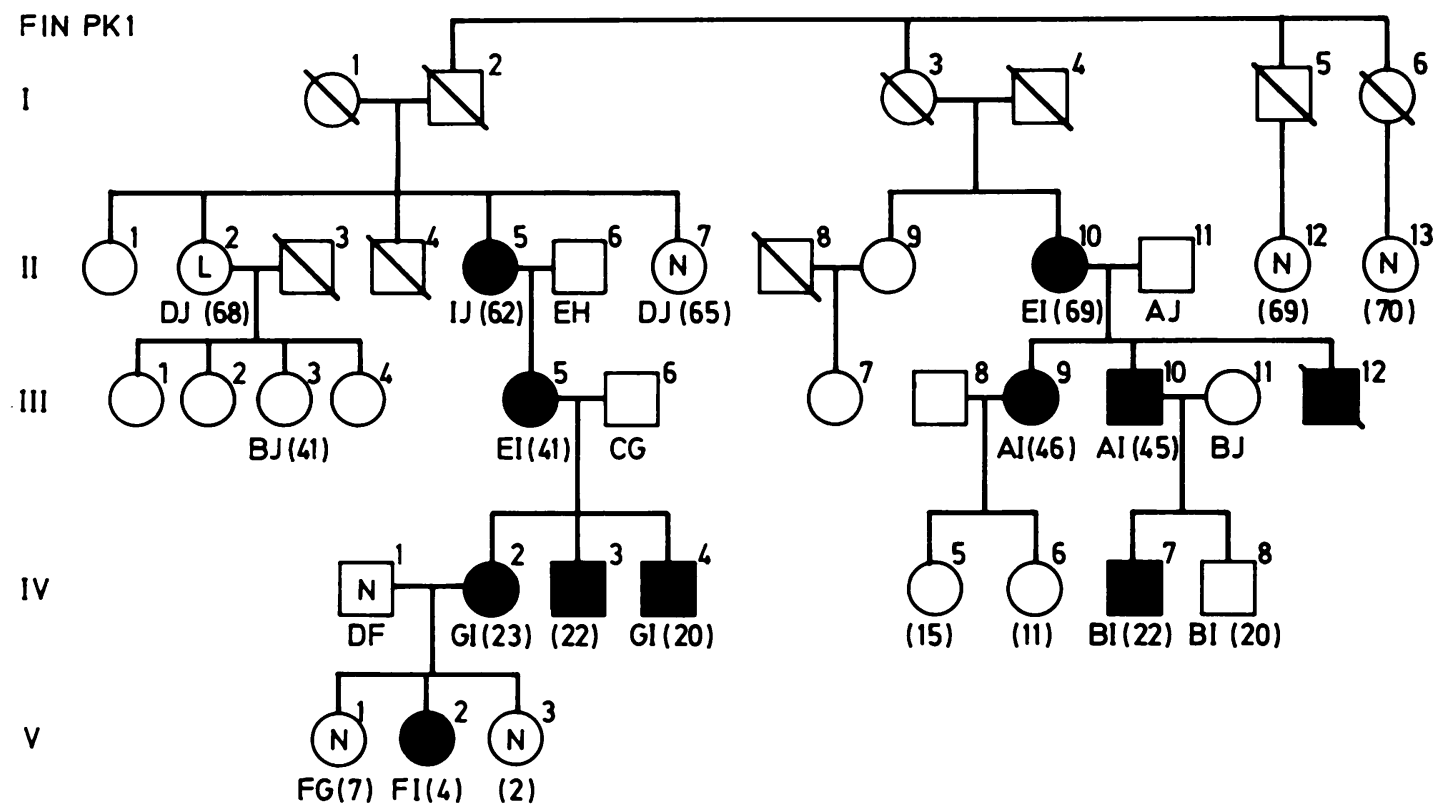

FIGURE Pedigree of family FIN PK1. Affected subjects are indicated by black symbols; ultrasound negative family members at risk are indicated by $N$ within the symbol. Subjects identified by empty symbols were not examined. II. 2 has multiple liver cysts but no renal cysts as indicated by the letter L. 3'HVR phenotypes are indicated by letters (alleles $A$ to $J)$ together with the ages of the subjects at the time of study.

proband were then examined by ultrasonography, and the mother (IV.2) was shown to have bilateral polycystic kidneys. Other members of the family at risk were subsequently examined by ultrasound after informed consent had been obtained. In all, 10 family members were shown to be affected as judged by the ultrasonographic criteria of Bear et $a l .^{12}$ These criteria were chosen because corresponding estimates of the sensitivity of ultrasound are available. Patients were considered to be affected if at least one cyst in each kidney and at least two cysts in one kidney were detected. None of the affected subjects was found to have symptomatic renal disease or reduced renal function. III.10 (aged 45) has had raised blood pressure with normal renal function for 10 years, but otherwise there is no family history of hypertension. IV.2 (now aged 23) suffered a subarachnoid haemorrhage two years ago at the age of 21. She was not found to be hypertensive.

The present study illustrates some of the difficulties in the diagnosis of APKD using imaging techniques. II.2 was asymptomatic with normal renal function at the age of 68 . Ultrasonography showed multiple hepatic cysts but no renal abnormality. CT imaging also failed to detect cysts in the kidneys, but confirmed the presence of multiple hepatic cysts. Her daughter, III.3, was found to have one $5.5 \mathrm{~cm}$ renal cyst but no other renal or hepatic changes. Although it is likely that the presence of multiple hepatic cysts in II.2 indicates that she has inherited the APKD mutation despite the lack of renal cysts, the precise significance of hepatic cysts in the absence of renal cysts has not been assessed. Similarly the significance of a single renal cyst in III. 3 in the context of the parental and familial risk of APKD is not known. The criteria used to determine the phenotype in this study do not take the presence or absence of hepatic cysts into account. Thus, II.2 and III. 3 are considered to be normal for the purposes of linkage analysis.

DNA STUDIES

A highly polymorphic DNA sequence, ${ }^{13}$ the $3^{\prime}$ hypervariable region of the $\alpha$ globin locus ( $3^{\prime}$ HVR), was used, as in previous genetic linkage studies. ${ }^{9}$ This region consists of a tandemly repeated 17 base pair sequence, approximately 8 kilobases (kb) beyond the $3^{\prime}$ end of the $\alpha$ globin gene cluster. Polymorphism at this locus is attributed to variability in the copy number of the elements of the repeat. Using the Southern blotting technique, ${ }^{14}$ 
a ${ }^{32} \mathrm{P}$ labelled Hinf $\mathrm{I}$ fragment including approximately $4 \mathrm{~kb}$ of the $3^{\prime} \mathrm{HVR}$ was hybridised to $P v u \mathrm{II}$ digested genomic DNA. The probe hybridised to two allelic fragments in each subject. Genotypes of members of FIN PK1 are shown in the figure.

LINKAGE ANALYSIS

Linkage analysis was carried out using the computer programme MLINK. ${ }^{15}$ An age of onset (detection) curve was used to allow for the age dependent sensitivity of ultrasonography as described previously. ${ }^{9}$

\section{Results}

Pedigree FIN PK1 is shown in the figure. Ten electrophoretically distinguishable $3^{\prime} \mathrm{HVR}$ alleles were observed. These are indicated by the arbitrary letters A to J. The APKD mutation segregates with the $2.4 \mathrm{~kb}$ allele (I) in this family. The maximum lod score $(\hat{Z})$ was 2.61 at a recombination fraction $\hat{\theta}=0 \cdot 00$. Thus there is strong evidence in favour of close linkage between the $3^{\prime} \mathrm{HVR}$ region of the $\alpha$ globin locus and the mutation producing the atypical form of APKD observed in this family. The ages of individual members are indicated in parentheses. Because of the difficulty of visualising small cysts using imaging techniques, and because small cysts tend to be present in the first two decades of life, the phenotypes of apparently normal subjects must be interpreted with respect to their age. This is especially important for persons under 15 years of age, since the sensitivity of diagnosis is markedly reduced in this group. It should be noted that, according to the criteria used for diagnosis (see Patients and methods), subjects II.2 and III.3 are considered to be normal and are therefore nonrecombinants. If the diagnosis in these cases is incorrect, at least one crossover must have occurred and the maximum lod score will be reduced accordingly.

\section{Discussion}

A number of large necropsy series have drawn attention to the fact that the frequency of APKD in randomly selected necropsy cases is higher than would be expected from estimates of the clinical incidence of the disease. ${ }^{5}$ There are a number of possible explanations. First, it has been found that a number of these patients were symptomatic during life and had a family history suggestive of typical APKD. ${ }^{16}$ It is possible, therefore, that these cases represent instances of failure to detect and treat the disease during life. Second, the occurrence of multiple bilateral simple cysts may account for some of the cases described as polycystic kidney disease at necropsy. Hatfield and Pfister ${ }^{16}$ attempted to exclude such cases at necropsy by insisting that, for a reliab度 diagnosis of APKD, extrarenal cysts should be present. Even so, they found a substantial number of cases of polycystic kidney disease, some of which had been asymptomatic during life. It appears from these and other similar observations that a substang tial fraction of the polycystic kidney disease incidentally found at necropsy represents asymptomatie cases. Previously, family studies have not beem carried out to determine whether these asymptoma tic cases were members of families in which othêु subjects had typical symptomatic APKD, of whether they came from families in which on asymptomatic disease is found. Hatfield and Pfiste found that only one of the 32 necropsy cases i which there were no apparent symptoms during liff had a family history of APKD. This suggests that many of these cases may have been sporadic or may not have been inherited in an autosomal dominar manner. However, since the necropsy subjects themselves were not found to have cysts during life? it is possible that a family history of APKD might not have been obtained by interview alone and that imaging of family members will be needed to resolve the issue of whether these are truly sporadic cases Here we present a study designed to answer some of these questions. A family was identified in which number of subjects with the morphological features of polycystic kidney disease were found to b? asymptomatic. Examination of members of the्Q extended pedigree showed that none of the subjects at risk was symptomatic, and none had reduce renal function. The disease was clearly segregating as an autosomal dominant trait in this family Linkage studies were carried out in order to dete? mine whether the localisation of the mutation producing this form of the disease was consisten with the localisation of the mutation producing typical symptomatic disease. The evidence presented here shows that both forms of the disease are closely linked to $\alpha$ globin and suggests that the mutations producing the disease occur within the same gene or group of genes. We cannot, howevef exclude the possibility that the mutations producing these two forms of the disease are both coince dentally localised on the short arm of chromosome 16 and are both linked to $\alpha$ globin. Ultimately, the identification of the APKD gene (or genes) wit provide the answer as to whether or not the two mutations are actually arlelic.

The absence of functional renal impairment asso ciated with the presence of polycystic kidneys is remarkably constant feature in this family. Furthe⿻ studies are required to determine whether this found in other families in which there ar 
asymptomatic members. Such information would be of great importance in the genetic counselling of this disease. It is important to note, however, that the mother of the proband sustained a subarachnoid haemorrhage during the course of the study. Thus the prognosis for extrarenal manifestations of APKD may have to be considered separately from the prognosis for renal failure.

We are grateful to the' Polycystic Kidney Research Foundation (Kansas City, Missouri), the Georg and Ella Ehrnrooth Foundation, the National Kidney Research Foundation, and the Wellcome Trust for support. Andrew King assisted with linkage analysis and Rachel Kitt prepared the manuscript.

\section{References}

1 Weatherall DJ. ed. The new genetics and clinical practice. 2nd ed. Oxford: Oxford University Press. 1986.

2 Levey AS. Pauker SG, Kassirer JP. Occult intracranial ancurysms in polycystic kidney disease. $N$ Engl $J$ Med 1983:308:986-94

' Gardner KD. Evan AP. Cystic kidneys: an enigma evolves. Am J Kidney Dis 1984:111:403-17.

+ Zerres K. Volpel MC. Weiss H. Cvstic kidnevs: genetics. pathologic anatomy, clinical picture, and prenatal diagnosis. Hum Genet 1984:68:104-35.

5 Torres VE, Holley KE. Offord KP. General features of autosomal dominant polycystic kidney disease. A. Epidemiology. In: Grantham JJ, Gardner KD, eds. Problems in diagnosis and management of polycystic kidney disease. Kansas City. PKR Foundation, 1985:49-69.

${ }^{\circ}$ Dalgaard OZ. Bilateral polycystic disease of the kidneys. A follow up of 284 patients and their families. Acta Med Scand 1957:328:1-233.

7 Churchill DN. Bear JC. Morgan J. Paync RH. McManamon PJ. Gault MH. Prognosis of adult onset polycystic kidney disease reevaluated. Kidney Int 1984:26:190-3.

" Gabow AP. Ikle DW. Holmes JH. Polycystic kidney discase: prospective analysis of nonazotacmic patients and family members. Ann Intern Med 1984:101:238-47.

"Reeders ST. Breuning MH. Davies KE, et al. A highly polymorphic DNA marker linked to adult polycystic kidney disease on chromosome 16. Nature 1985:317:542-4.

1" Reeders ST. Breuning MH. Corney G. et al. Two genetic markers closely linked to adult polycystic kidney disease on chromosome 16. Br Med J 1986:292:851-3.

"Recders ST. Breuning MH. Ryynanen MA. et al. A study of genetic linkage heterogeneity in adult polycystic kidney disease. Trans Assoc Am Physicians 1986;99:154-60.

12 Bear JC. McManamon P. Morgan J. et al. Age at clinical onset and at ultrasonographic detection of adult polycystic kidney disease - data for genetic counselling. Am J Med Genet 1984:18:45-53.

1.3 Jarman AP. Nicholls RD. Weatherall DJ. Clegg JB. Higgs DR. Molecular characterisation of a hypervariable region downstream of the human a-globin gene cluster. EMBO J 1986:5:1857-63.

${ }^{1+}$ Southern EM. Detection of specific sequences among DNA fragments separated by gel electrophoresis. J Mol Biol 1975:98:503-17.

15 Lathrop GM. Lalouel JM. Julier C. Ott J. Strategies for multilocus linkage analysis in humans. Proc Natl Acad $S_{c i}$ USA 1984:81:3443-6.

16 Hatficld PM. Pfister RC. Adult polycystic disease of the kidneys (Potter type 3). JAMA 1972:222:1527-31.

Correspondence and requests for reprints to Dr S T Reeders, Nuffield Department of Clinical Medicine, John Radcliffe Hospital, Headington, Oxford OX3 9DU. 